\title{
Sound Radiation Analysis of a Guitar Cover by the Finite Element Method
}

\author{
José M. C. Dos Santos (PQ), Felipe M. do Nascimento (IC).
}

\section{Abstract}

This project of scientific iniciation had the goal of an evaluation by finite element method (FEM) of the sound radiation of a guitar cover. It consists in one analysis of a simple cover (isotropic) followed by one analysis with orthotropic material. ABAQUS® and ANSYS® were the programs used for this.

Key words: Finite Element Method, Vibro-Acoustics, Vibration Modes.

\section{Introduction}

The basic concepts of vibro-acoustics were studied $^{1}$, as well as the definition of natural frequencies on thin boards. Analytics equations of natural frequencies for thin boards with different boundary conditions were get from Blevins ${ }^{2}$.

The beginning of the study was about the simple case of an isotropic board (steel). Then, the material was changed to an orthotropic (white fir) that is commonly used at guitar's covering.

\section{Results and Discussion}

The board with the dimensions of $0.5 \times 0.75 \times$ $0.002 \mathrm{~m}$ was modeled on ABAQUS and ANSYS. The results were compared with those obtained with analytics equations from Blevins. The Chart 1 shows the orthotropic case with errors lower than $0.5 \%$ between the MEF and the analytic equation. Figure 1 shows the second mode of the board.

Chart 1. Orthotropic board: clamped.

\begin{tabular}{|c|c|c|c|c|c|c|c|}
\hline \multirow{2}{*}{ Modo } & \multirow{2}{*}{$i$} & \multirow{2}{*}{$j$} & \multicolumn{5}{|c|}{ Bordas Engastadas - Frequência [Hz] } \\
\cline { 5 - 8 } & & & Blevins & \multicolumn{2}{|c|}{ ABAQUS } & \multicolumn{2}{|c|}{ ANSYS } \\
\hline & & Analitica & Eng, Const & Erro[\%] & Ortotrópica & Erro[\%] \\
\hline 1 & 1 & 1 & 27,552 & 27,480 & 0,260 & 27,479 & 0,263 \\
\hline 2 & 1 & 2 & 41,742 & 41,604 & 0,330 & 41,606 & 0,325 \\
\hline 3 & 1 & 3 & 67,187 & 66,915 & 0,410 & 66,948 & 0,356 \\
\hline 4 & 2 & 1 & 68,357 & 68,148 & 0,310 & 68,150 & 0,302 \\
\hline 5 & 2 & 2 & 79,831 & 79,520 & 0,390 & 79,543 & 0,360 \\
\hline 6 & 2 & 3 & 101,351 & 100,944 & 0,400 & 101,030 & 0,317 \\
\hline 7 & 1 & 4 & 102,989 & 102,479 & 0,490 & 102,650 & 0,329 \\
\hline 8 & 3 & 1 & 130,514 & 130,078 & 0,330 & 130,100 & 0,317 \\
\hline 9 & 2 & 4 & 133,841 & 133,162 & 0,510 & 133,440 & 0,299 \\
\hline 10 & 3 & 2 & 140,931 & 140,305 & 0,440 & 140,380 & 0,391 \\
\hline
\end{tabular}

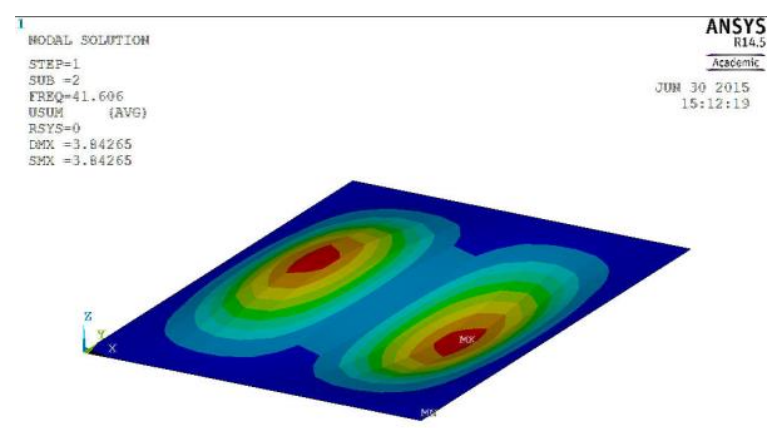

Figure 1. Second mode of the clamped orthotropic board
Figure 2 shows the first four vibration modes of linked system (structure-fluid) calculated by MEF (ANSYS) to the isotropic (steel) thin board linked to a layer of fluid (air) of $0.5 \mathrm{~m}$. The results are consistent with those found in the literature but still require a qualitative comparison.

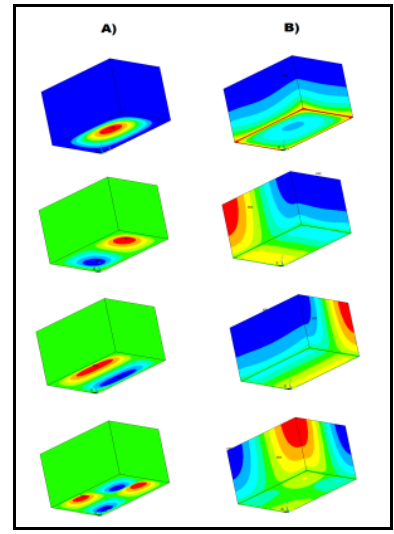

Figure 2. Vibration modes of the linked system: (A) Structural and (B) Acoustic.

\section{Conclusions}

A study of an actual engineering problem in the coupling areas (vibro-acoustics) was done. In this case was learned modeling by MEF which is very important to the learning process and initiation of the current research engineer.

\section{Acknowledgement}

The authors are grateful to PIBIC/CNPq.

\footnotetext{
1 Barron, R., "Industrial Noise Control and Acoustics", Marcel Dekker, New York, 2003.

2 Blevins, R., "Formulas for Natural Frequency and Mode Shape", Krieger Publishing Company, Florida, 2001.

${ }^{3}$ Bergman, R, et al , "Wood Handbook-Wood as an Engineering Material", General Technical Report FPL-GTR190, Madison, WI, 508 p., 2010.
} 